\title{
Co-Infection of Babesia bigemina and Ehrlichia sp. in a Holstein Friesian Bull - A Pathomorphological Report
}

\author{
N. Jayanthi ${ }^{1 *}$, R. Saahithya ${ }^{1}$, N. Pazhanivel ${ }^{1}$ and C. Balachandran ${ }^{2}$ \\ ${ }^{1}$ Department of Veterinary Pathology, Madras Veterinary College, TANUVAS, Chennai - 7, \\ Tamil Nadu, India \\ ${ }^{2}$ Tamil Nadu Veterinary and Animal Sciences University, Chennai - 51, Tamil Nadu, India \\ *Corresponding author
}

\section{A B S T R A C T}

\begin{tabular}{|l|}
\hline Ke y w o r d s \\
$\begin{array}{l}\text { Bull, Holstein Friesian, } \\
\text { Ehrlichia sp., Babesia } \\
\text { bigemina, } \\
\text { Pathomorphology }\end{array}$ \\
\hline Article Info \\
\hline $\begin{array}{l}\text { Accepted: } \\
18 \text { May } 2018 \\
\text { Available Online: } \\
\text { 10 June } 2018\end{array}$ \\
\hline \hline
\end{tabular}

\begin{abstract}
A pure bred imported Holstein Friesian bull aged 4.5 years was brought for necropsy with a history of treatment for suspected anaplasmosis. Gross examination revealed a dehydrated carcass with pale mucous membranes. Pericardial sac contained about $75 \mathrm{~mL}$ of serosanguineous fluid. Myocardial and subendocardialecchymotic haemorrhages were seen in the heart. Lungs revealed patchy lobulated pattern and thickening of interlobular septa and emphysematous areas. Hepatic parenchyma was firm and tan yellow brown. Gall bladder contained about $25 \mathrm{~mL}$ of dark yellow green bile. Cortex and medulla of kidneys were dark red brown. Urinary bladder contained about 1.5 litres of coffee coloured urine suggesting haemoglobinuria. Peripheral and heart blood smears revealed Babesia bigemina in the erythrocytes and morula of Ehrlichia sp. in the monocytes with anaemic changes. Spleen imprints revealed macrophages with numerous Ehrlichia sp. Based on the above findings, the case was diagnosed as Babesiosis and Ehrlichiosis.
\end{abstract}

\section{Introduction}

Bovine Babesiosis and Ehrlichiosis are worldwide in distribution in cattle population transmitted by arthropod vectors (Mosqueda et al., 2012). It causes serious economic losses in cattle industry. Babesia sp. is intra erythrocyticobligate apicomplexan parasite highly prevalent in tropical and subtropical countries. Ixodid ticks mainly transmit the Babesia sp. (Allred, 2003; Purnell et al., 1976; Taylor et al., 1986; Homer et al., 2000). Ehrlichiosis in bovine is caused by Gram negative obligate intracellular bacteria belonging to the genus Anaplasma. Initially it was named as Ehrlichiabovis and later renamed as Anaplasmabovis (Prasath et al., 2016; Sreekumar et al., 1999). It causes serious disease in tropical countries, cross bred cattle and newly imported cattle. They occur in cytoplasm of the monocytes. It is mainly transmitted through the tick species of Ambylomma, Hyalomma and Rhiphicephalus. In India, Ehrlichiabovis is highly prevalent in Indian states (Ramesh et al., 2008; Chirayath et al., 2012; Nair et al., 2013).

Microscopical detection of the parasites are still the most cheapest and economic method in the detection of the parasite. Other 
immunological and serological methods can be made use of for further confirmation (Bock et al., 2006). The main objective of the present study is to discuss describe the co-infection, its microscopical detection, gross and histopathological findings in a bull.

\section{Materials and Methods}

\section{Necropsy examination}

A pure bred Holstein Friesian bull was presented to the Department of Veterinary Pathology, Madras Veterinary College with a history of sudden death. It was clinically suspected for anaplasmosis based on the signs. Preliminary history was obtained and necropsy examination was carried out.

\section{Collection of samples}

The tissue samples of $4 \mathrm{~mm}$ thickness of each were collected from heart, kidney, liver and spleen in 10 per cent formalin in wide mouthed bottles. After fixation, the samples were processed for histopathology. Paraffin embedded tissue sections were cut into $4 \mu \mathrm{m}$ thickness and stained with Haematoxylin and Eosin and it was viewed under light microscopy. Peripheral blood smears, heart blood smears and impression smear from spleen were collected in a clean grease free microscopic slide. It was air dried and stained with Leishman Giemsa stain solution for 30 minutes, air dried and viewed under oil immersion objective of light microscope.

\section{Results and Discussion}

\section{Blood smear examination:}

The presence of organisms are represented in the Fig. 9 and 10. The heart blood smear revealed a pair of Babesia bigemina parasite within the erythrocyte which were pyriform in shape and in acute angle and few were pleomorphic in shape. The parasitic burden was seen in almost 40 percent of the erythrocytes. The heart blood smear as well as the touch impression smears from spleen revealed the presence of a medium sized homogenous spherical dark blue colored Ehrlichia sp. morula in the cytoplasm of the monocytes. More than 60 per cent of the monocytes revealed parasitic burden.

\section{Gross pathology}

The gross morphology is represented in the Fig. 1 to Fig. 8. Necrospy examination revealed a dehydrated carcass with pale mucous membranes. Pericardial sac contained about $75 \mathrm{~mL}$ of sero-sanguineous fluid. Heart revealed myocardial and subendocardialecchymotic haemorrhages.

Lungs revealed patchy lobulated pattern and thickened interlobular septa with multifocal emphysematous areas. Liver was firm with tan yellow brown parenchyma. Gall bladder had about $25 \mathrm{~mL}$ of dark yellowish green coloredbile. Spleen was mildly enlarged, subcapsular vessels were congested and on incision it had dark red black parenchyma. Kidneys had dark red brown cortex and medulla. Urinary bladder was distended with about 1.5 litres of coffee coloured urine with serosal congestion.

\section{Histopathology}

The histopathology of the respective organs is represented in Fig 11 to Fig. 14. Microscopical examination revealed mononuclear cell infiltration in the hepatic parenchyma. Spleen revealed severe congestion and haemorrhage. Kidney showed congestion, tubular epithelial cell degeneration with mild interstitial nephritis. Congestion with focal haemorrhages were seen in the lymphnode. Heart revealed severe endocardial and myocardial haemorrhages. 
Fig.1 A 4.5 year old pure bred imported Holstein Friesian bull - dehydrated carcass; Fig.2 Heart - severe epicardial petechial to ecchymotichemorrhages; Fig.3 Heart - Severe diffuse endocardial hemorrhage; Fig.4 Lungs - Patchy lobulated pattern and thickening of interlobular septa and emphysematous areas; Fig.5 Liver -Firm with tan yellow brown parenchyma; Fig.6 Gall bladder contained about $25 \mathrm{~mL}$ of dark yellow green jelly like bile; Fig.7 Kidneys -Dark red brown cortex and medulla; Fig.8 Urinary bladder Distended and contained about 1.5 litres of coffee coloured urine with serosal congestion
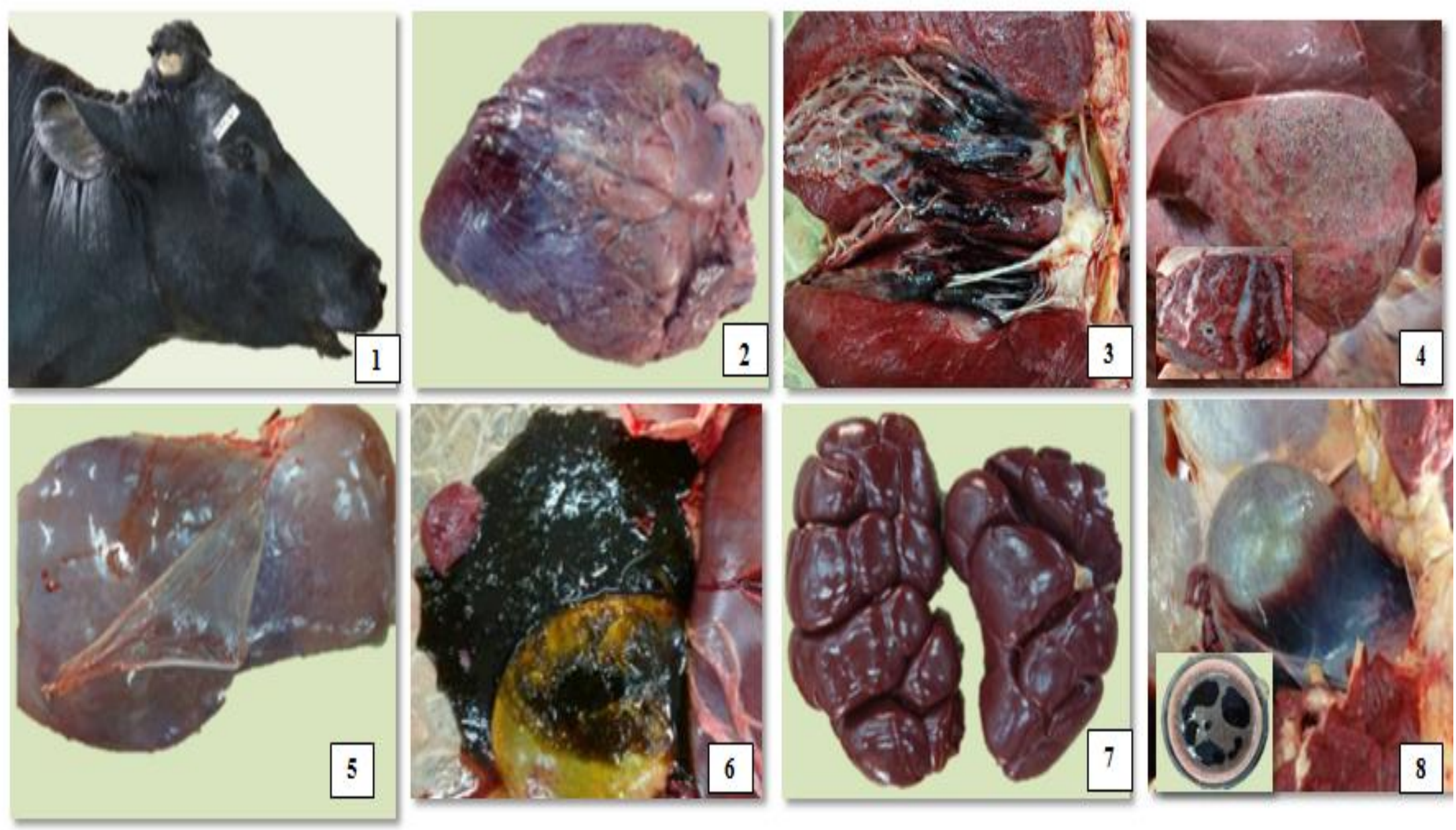
Fig.9 Heart blood smear revealed Babesiabigeminawithin the erythrocytes (Leishman \& Giemsa 100x); Fig.10 Heart blood smear revealed Ehrlichia sp. morula within the cytoplasm of the monocytes (Leishman \& Giemsa 100x); Fig.11 Liver - Mononuclear cell infiltration (H\&E 20x); Fig.12 Spleen - Severe congestion and haemorrhage (H\&E 20x); Fig.13 Heart - Severe Myocardial and endocardial hemorrhages (H\&E 20x); Fig.14 Kidney - Mild interstitial nephritis with tubular epithelial cell degeneration (H\&E 20x)
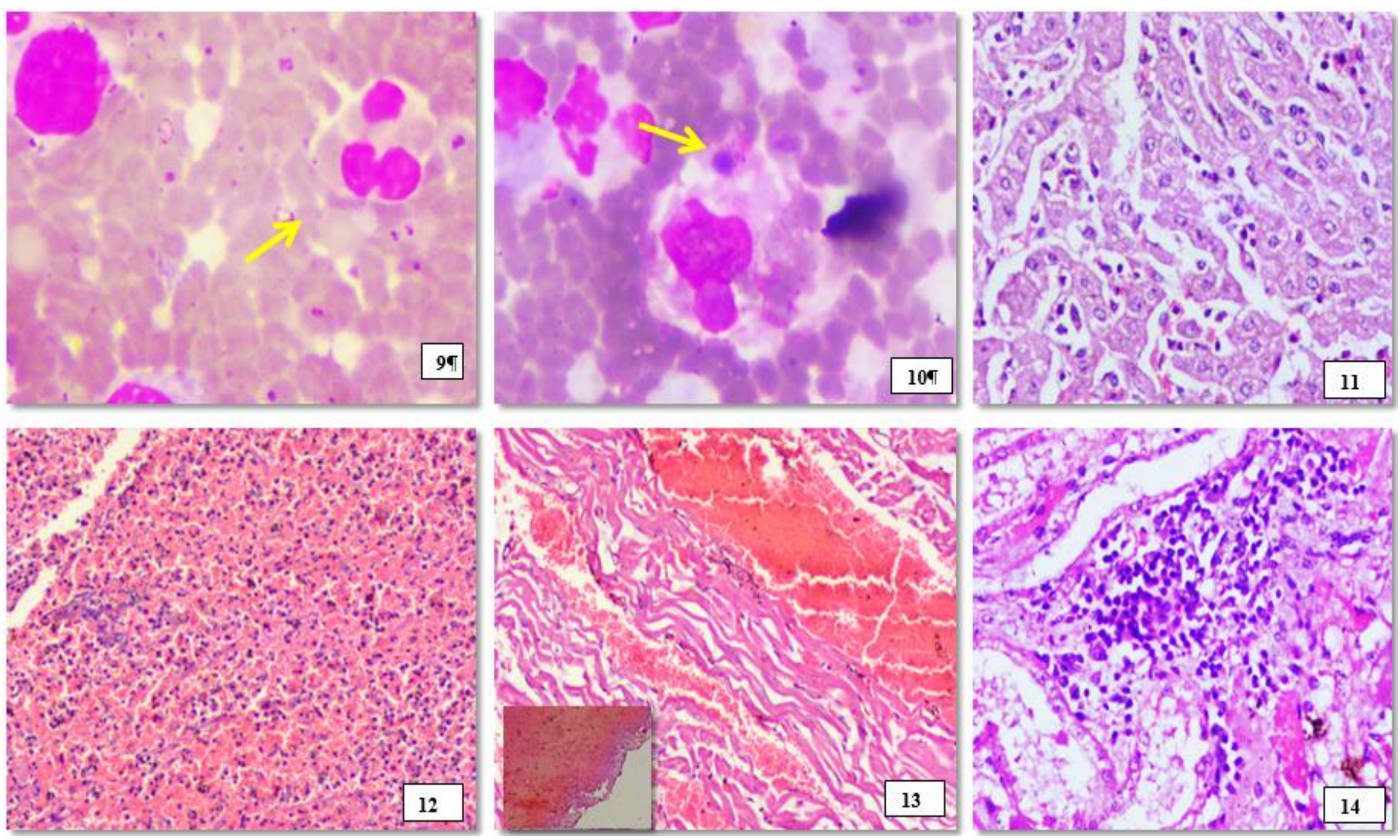
The occurrence of co-infection correlated with the previous reports of Ramesh et al., (2008) who described only the clinical and treatment aspects of the case in a cow. Wherein, this case describes the complete clinico-pathological, post mortem and histopathological findings in a bull. Another earlier report by Andersson et al., (2017) stated the co-infection of different strain of babesia and anaplasma (Ehrlichia) viz., Babesia divergens and Anaplasma phagocytophilum in cattle in Sweden.

The characteristic appearance of the organism in the blood smear was in agreement with the earlier reports (Sreekumar et al., 1999; Homer et al., 2000; Chirayath et al., 2012; Mosqueda et al., 2012 and Bock et al., 2012; Nair et al., 2013; Prasath et al., 2016; Ramadevi et al., 2017). However, Bock et al., (2012) reported that thick blood smears are more sensitive in detection of the parasite. But, in thepresent case, since the parasitaemia was higher than the average quoted levels, the thin blood smears obtained from the heart were good enough in detecting the parasite.

The gross and histopathological findings are in agreement with the pathological descriptions in previous reports (de Vos et al., 2004; Bock et al., 2012). The presence of haemoglobinuria, excessive granular and thick bile, haemorrhages over the epicardium and endocardium were the salient findings in this case suggestive of babesiosis. However, they have not reported the salient pathomorphological features in cases of coinfection. Hence, this report describes in detail the presence of co-infection and its corresponding gross and histopathological findings.

Hence, the present study describes the coinfection of Babesiosis and Ehrlichiosis in a bull and its gross and histopathological manifestations.

\section{Acknowledgement}

The authors acknowledge the facilities provided by the Tamil Nadu Veterinary and Animal Sciences University.

\section{References}

Allred, D.R., 2003. Babesiosis: persistence in the face of adversity. Trends in Parasitology. 19(2): 51-55.

Andersson, M.O., Víchová, B., Tolf, C., Krzyzanowska, S., Waldenström, J. and Karlsson, M.E. 2017. Co-infection with Babesia divergens and Anaplasma phagocytophilum in cattle (Bostaurus). http://dx.doi.org/10.1016/j.ttbdis.2017.0 8.005

Bock, R.E., deVos, A.J. and JB Molloy, J.B. 2006. Tick-borne diseases of Cattle. Australian and New Zealand Standard Diagnostic Procedures. Pp. 1 - 29.

Chirayath, D., Lakshmanan, B., Pillai, U.N., Alex, P.C. and Rejitha, T.S.2012. Anaplasma Bovis Infection in a Cow A Case Report. Journal of Veterinary and Animal Sciences. 43: 83-84.

DeVos, A.J., De Waal, D.T. and Jackson, L.A. 2004. Bovine babesiosis. In: Coetzer JAW, Tustin RC, editors. Infectious diseases of livestock. Oxford University Press, Capetown. pp. 406424.

Homer, M.J., Aguilar-Delfin, I., Telford Iii, S.R., Krause, P.J., and Persing, D.H. 2000.Babesiosis. Clinical Microbiology Reviews. 13(3): 451-469.

Mosqueda, J., Olvera-Ramírez, A., AguilarTipacamú, G. and Cantó, G.J. 2012. Current Advances in Detection and Treatment of Babesiosis. Current Medicinal Chemistry. 19: pp. 15041518.

Nair, A.S., Ravindran, R., Lakshmanan, B., Sreekumar, C., Kumar, S.S., Raju, R., Tresamol, P.V., Vimalkumar, M.B. and 
Saseendranath, M.R. 2013.Bovine carriers of Anaplasma marginale and Anaplasma bovis in South India. Tropical Biomedicine 30(1): 105-112.

Prasath, N.B, Selvaraj, J., Jeyathilakan, N., Saravanan, M., Saravanan, M., Basheer Ahamad, D. and Sasikala, M. 2016. Occurrence of Anaplasma bovis (Ehrlichiabovis) with varying morphology in a crossbred cow in Tamilnadu, India. Indian Journal of Veterinary Pathology. 40(2): 165-167.

Purnell, R.E., Brocklesby, D.W., Hendry, D.J., Young, E.R., 1976. Separation and recombination of Babesia divergens and Ehrlichia phagocytophila from a field case of red water from Eire. Veterinary Record. 99: 415-417.

Ramadevi, P., Ramakrishna, K.V. and Vijayabhaskar, A. 2017. Clinico pathological and therapeutic report on Babesiosis in buffaloes. Journal of Entomology and Zoology Studies. 5(5): 1752-1754.

Ramesh, S., Rajendran, A., Veeraselvam, M., Rajesh, N.V. and Jayathangaraj, M.G. 2008. Concurrent infection of Babesia bigemina and Ehrlichiabovis in a cow. Indian Veterinary Journal. 85: pp. 543.

Sreekumar, C., Anandan, R. and Balasundaram, S. 1999. Incidence of Ehrlichiabovis infection in Tamil Nadu. Indian Journal of Animal Science. 69: 1005-1007.

Taylor, S., Elliott, C. and Kenny, J. 1986. Babesia divergens: sequential exposure to heterologous tick-borne challenge of cattle immunized with a fraction of parasitized erythrocytes. Journal of Comparative Pathology. 96: 101-107.

\section{How to cite this article:}

Jayanthi N., R. Saahithya, N. Pazhanivel and Balachandran C. 2018. Co-Infection of Babesia bigemina and Ehrlichia sp. in a Holstein Friesian Bull - A Pathomorphological Report. Int.J.Curr.Microbiol.App.Sci. 7(06): 2023-2028. doi: https://doi.org/10.20546/ijcmas.2018.706.239 